\title{
Poder nas organizações: uma visão psicanalítica sobre influências nos líderes
}

\author{
Power in organizations: a psychanalytic overview about influences on leaders
}

\section{Adler de Macedo Berenstein e Thalita Lacerda Nobre ${ }^{2}$}

Resumo: $O$ presente estudo tem como objetivo compreender os elementos inconscientes que permeiam as relações de poder no ambiente organizacional, tendo como foco os trabalhadores em posição de liderança. Iniciando com uma contextualização psicanalítica sobre as sociedades e as relações de poder nelas presentes, o estudo parte para a análise das influências destas relações na vida e no comportamento dos sujeitos nelas inseridos, trazendo considerações a respeito das formas de trabalho nas empresas, seus vocabulários específicos e como as lideranças são vistas pelas organizações. $O$ método em questão envolve pesquisa bibliográfica revisando títulos que tratem a respeito dos conceitos de liderança, inconsciente dos líderes e relações grupais, com base psicanalítica. Os resultados obtidos mostram que os sujeitos na organização estão passíveis de exclusão em caso de discordância da cultura organizacional e do não seguimento das regras não ditas, porém impostas pela instituição, bem como a importância do mundo interno dos líderes.

\begin{abstract}
The purpose of this study is to understand the unconscious elements that permeate power relations in an organization, focusing on their leaderships. Starting with a psychoanalytic contextualization about societies and power relations present in them, the study goes on to analyze these influences on people's lives and behavior, considering about the ways of work in companies, their specific vocabularies and how leaders are seen by organizations. The method consists in bibliographic research reviewing titles related to leadership, unconscious of leaders and group relations, with a psychoanalytic basis. The results show that workers in an organization are likely to be excluded in case of disagreement with the organizational culture and by not following the non said rules that are imposed by the organization, as well as the importance of the leader's inner world.
\end{abstract}

Keywords: Leadership; Psychoanalysis; Power Relationships.

Palavras-chave: Liderança; Psicanálise; Relações de Poder.

\footnotetext{
1 Bacharel em Psicologia pela Universidade Católica de Santos. E-mail: adlerberenstein@gmail.com

2 Doutora em Psicologia Clínica pela PUC-SP e docente titular na Universidade Católica de Santos.

E-mail: thalita.nobre@unisantos.br
} 


\section{Introdução}

Ao observarmos um ambiente organizacional é possivel perceber que as empresas abrigam em suas estruturas hierárquicas, espaços físicos e discursos, as marcas das relaçoes de poder ali presentes. Isto é perceptível quando analisamos as regras às quais os trabalhadores em diferentes posições são submetidos e os privilégios concedidos a poucos. Além disso, questionamentos como"Por que os sujeitos se submetem a certas relaçōes de trabalho?" e o"Por que reproduzimos relações hierárquicas em todos os lugares? " contribuirão para 0 entendimento dessa pesquisa.

0 que chama a atenção para 0 tema não é apenas o reconhecimento dessas marcas, mas sim a influência delas na atuação e na vida dos trabaIhadores. As relações de poder não estão somente entre líder-liderado, mas também abarcam questões de gênero e a ligação da própria instituição com o trabalhador. Em “A banalizaçã̃o da injustiça social", (Dejours, 1998) nota-se como o próprio trabalho (e a forma como ele se modifica) influencia e insere imposições na vida do trabalhador. Novos modelos de trabalho oriundos das reformas estruturais propiciam o surgimento de condiçoes dolorosas e de adoecimento, distorcendo 0 trabalho bem feito, o sentido da responsabilidade e da ética profissional: "Ser constrangido a executar mal o seu trabalho, a atamanca-lo ou a agir de má-fé é uma fonte importante e extremamente frequente de sofrimento no trabalho [...]"'(Dejours, 1998, p. 32).

Quando a visão sobre a organização e sobre o trabalhador éfocada apenas em seus resultados perde-se o contato com a visão integral do ser humano, empobrecendo o espaço para pensar o seu bem-estar, já que o pensar, não de hoje, passou a ser algo voltado à produtividade e à objetividade. As regras das instituições contribuem para que a criticidade do ser esteja diretamente ligada àquilo que produz mais, aos métodos que podem ser revisados com 0 objetivo de melhoria contínua e excelência.

São as interações humanas que dão espaço para conceitos postulados inicialmente por Freud, como a transferência e a contratransferência, a projeção e introjeção, e quando falamos de uma empresa a situação não é diferente, basta que as pessoas estejam presentes na organização e se relacionem para que existam estas díades.

Com o objetivo de levantar e compreender os elementos inconscientes que permeiam as relações de poder no ambiente organizacional, com foco nos trabalhadores em posição de liderança, este trabalho se debruça sobre o histórico psicanalítico das relaç̧ões de poder, partindo de uma análise do "pai totêmico"de Freud, com breve passagem pelo"Nome-do-pai”para Lacan, buscando compreender de forma mais abrangente o mundo interno dos líderes e a relação destes com as organizaçōes, sempre na busca por respostas e comprovaçôees do que se acredita: discurso e cultura organizacionais aliados aos poderes conferidos a determinados cargos influenciam o modo de agir do trabalhador direcionando-0 para uma função de retransmissor passível de exclusão caso não a cumpra. Deve-se registrar a dificuldade encontrada pela aproximação ao tema, de não tecer críticas aos modelos de trabalho atuais e as formas de atuação das lideranças, localizando na obra de Dejours berço para demais reflexões.

\section{Método}

0 método em questão envolve pesquisa bibliográfica revisando títulos que tratem a respeito dos conceitos de liderança, inconsciente dos líderes e relações grupais, com base psicanalítica.
Os critérios utilizados para esta pesquisa bibliográfica foram: obras que relacionem a psicanálise com o social e as organizações, juntamente com a base de dados Scielo, e que envolvam como palavras chave os termos Psicanálise, Trabalho, Organização e Poder e Liderança. 0 período escolhido varia de 1913, com a obra Totem e Tabu, de Freud, e, para artigos científicos utiliza-se como referência 0 ano de 2010 até 0 momento atual.

\section{Histórico psicanalítico e a posição do pai dentro dos grupos}

Para iniciarmos, Freud em sua obra "Totem e Tabu" (1912 - 1913), traz a consideração de que o sistema totêmico está presente como representação anterior às instituições sociais e religiosas. Por mais primitivos que os grupos sejam, existe a meta de evitar as relações incestuosas, com rituais de distanciamento nas tribos, como exemplo um homem que ao avistar uma mulher de mesma tribo (mesmo totem) / laço sanguíneo, caminhando sozinha, esconde-se atrás das folhas de um arbusto até que ela passe. Para estas tribos, "membros do mesmo totem não podem manter relações sexuais entre si, ou seja, de que também não podem se casar uns com os outros [...] A desobediência à essa proibição [...] é punida da maneira mais enérgica por toda a tribo, como se se tratasse de afastar um perigo que ameaçasse toda a comunidade" (Freud, 1912-1913, pp. 40 - 41).

Freud (1912-1913) nos conta também que membros de um mesmo totem possuem sagrado compromisso em não destruir ou obter qualquer usufruto de seu totem (que não necessariamente reside em um animal ou ser específico, mas sim em todos os representantes de uma espécie). Com relação ao tabu, é considerado que ele traga uma força mágica capaz de vincular as pessoas e espíritos e que esta força tem a capacidade de ser transmitida por objetos inanimados. 0 significado de tabu por sua vez é originário de uma palavra polinésia cuja tradução não possui mais estrita relação com o conceito original, assumindo dois vieses: o daquilo que é sagrado ou o proibido, impuro e perigoso.

De acordo com Freud, o resultado de uma violação do tabu não depende somente da força mágica aderente ao objeto tabu, mas também da intensidade do mana (a força mágica) que no transgressor se opõe a essa força. Seguindo este raciocínio, reis e sacerdotes são possuidores de uma enorme força que significaria a morte para seus súditos se entrassem em contato direto com eles, precisando de um mediador que mais se assemelha a um ministro dotado de mana também superior, podendo se relacionar com os líderes sem perigo."A importância de tabus comunicados também depende do mana da pessoa de quem procedem; quando um rei ou um sacerdote impõe um tabu, este é mais eficaz do que se proviesse de um homem comum" (Freud, 1912-13, p. 61).

Mas o que todas estas reflexões sobre o clã totêmico, o funcionamento das relações por intermédio do mana, e a força do tabu nos dizem a respeito do mundo das organizaçōes? Se existe relação entre esses mundos, qual seria ela?

Em princípio esta ligação pode parecer distante, mas se considerarmos o funcionamento filogenético do ser humano, a atuação em sociedade segue reproduzindo os comportamentos e as regras aplicadas aos grupos totêmicos. Mudaram-se os totens, mas os tabus continuam tendo a mesma função e 0 peso quiçá maior (fora o chiste com a "colocação do falo na mesa", que independe do gênero e nas organizações está associado à demonstração de poder). 
Na organização, a cultura organizacional seria o totem, aquilo que "protege" 0 trabalhador, mas ao mesmo tempo é a regra que transmite a ideia de punição automática se não a respeitar. 0 mana éa energia que permanece funcionando como uma espécie de cola, unindo os grupos. Já o líder se assemelha à figura do sacerdote, aquele cuja energia é tão alta que os membros mais fracos do grupo precisam de mediadores nas relações. Estes mecanismos de relação dos sujeitos no grupo nos remetem às estruturas hierárquicas das empresas. Freud refere que o tabu de um rei é forte o suficiente para seu súdito pois a distância social entre eles é muito grande, mas o ministro pode fazer o papel mediador: "quanto ao ministro, pode moderar sua inveja em relação ao rei considerando o poder que a ele próprio foi concedido. Assim, diferenças menores na força mágica que induz à tentação são menos temíveis [...]" (Freud, 1912-1913, p. 76).

Em ocasião da decadência do pai totêmico, deste líder, o trabalhador deve alimentar-se de sua energia como forma de incorporação daquela figura, assumindo sua força, e sempre garantindo a legitimidade da figura de poder. Portanto, a conciliação simbólica, ou seja, a aceitação da figura do pai ou da mãe, não significa que seja necessário conviver com aqueles que podem ter gerado muito sofrimento, mas sim a aceitação de que está integrado dentro de si a libertação da submissão que estes causavam, a libertação da autoridade e da dependência para que o sujeito seja capaz de viver a vida adulta. Mas será mesmo que há essa liberdade ou o sujeito em uma tentativa de reviver esta relação procura na organização por figuras de autoridade para novamente estar submisso à regra externa e não à sua própria, já que o desenvolvimento da tomada de consciência por pensamento e reflexão é doloroso e requer grande movimento psíquico.

Para que não haja confusão com o uso da palavra pai, deixemos claro que não se trata aqui do pai propriamente dito como figura masculina detentora do poder, "trata-se menos da presença ou ausência de um pai real, mas de um lugar no discurso materno e de sua significação para a criança. Remete à "função paterna", o representante da lei, que interdita 0 acesso onipotente da criança à mãe" (Folberg \& Maggi, 2002, p. 93). Ainda de acordo com estas autoras, é por meio da análise dos diferentes significados que esta função exerce que podemos designar desde um lugar do pai biológico ao lugar da representação simbólica da lei, dos valores e dos ideais de vida do sujeito.

A partir do momento que ocorre a transposição do pai "castrador" é que o sujeito será capaz de expressar toda a sua potencialidade e o conteúdo já nomeado pela função materna: "Falar em "declínio da função paterna" significa situar os representantes subjetivos da constelação familiar, incluindo pai, mãe e filho, com suas características físicas, da ordem de nascimento na família e da rede significante desses múltiplos personagens" (Folberg \& Maggi, 2002, p. 94). Declínio de uma função paterna que também sofreu alterações no decorrer do tempo, embora ainda apresente sua importância.

Podemos correlacionar com o conceito de "Nome-do-pai" proposto por Lacan, como a forma de compreensão da realidade, sendo este uma cadeia significante que se assemelha a uma imensa frase que explica a realidade. O Nome-do-pai é a "última palavra" que precisamos para entender a cadeia significante. Nas mãos de Lacan esta visão parece sugerir uma interpretação mais patriarcal e fálica da realidade, na qual "A mulher não existe", pois, os homens possuem o símbolo que os representa no universo ao passo que a mulher não. 0 Nome-do-pai teria então a função de não permitir a queda do sujeito no mecanismo de forclusão "que estaria na origem do fato psicótico; consistiria numa rejeição primordial de um "significante" fundamental para fora do universo simbólico do sujeito". (Laplanche \& Pontalis, 2001, p. 195). Sem a integração do Nome-do-pai ao inconsciente do sujeito, não há inserção no ambiente social e organizacional.

\section{A respeito da liderança}

A liderança exige competências profissionais e até mesmo pessoais que não chegam a ser acessíveis a todos, e não é tarefa complicada encontrar pessoas com essas competências nos mais inusitados lugares. Nosso foco está nas lideranças em níveis gerenciais, trabalhadores nesta posição hierárquica que implica, segundo Gomes (2017, p. 84), em "pessoas cuja atuação depende o funcionamento de um sistema de gestão, a direção de um setor, departamento, ou mesmo da empresa".

Um cargo não é uma garantia. A tribo precisa reconhecer o mana do líder como poderoso, logo, um líder vai até onde o reconhecem como tal. Paul Spector (2012, p 346) nos traz uma ideia de liderança que "envolve influenciar as atitudes, crenças, comportamentos e sentimentos dos outros. Pessoas que não são líderes também influenciam os outros, mas os líderes exercem uma influência desproporcional". Lapierre (1995) nos diz que, por não pertencer somente ao líder, o fenômeno liderança precisa de uma ligação entre as visões de um líder e os desejos daqueles que o acompanham. Segundo Nobre (2017), um líder surge a partir do reconhecimento pelos outros e por si mesmo em seu comportamento, não apenas porque a organização o designou assim.

Gomes (2017, p. 84) dirá que sobre o tema liderança paira na atualidade uma espécie de aura mítica, legitimando o discurso de que somente pessoas eleitas, especiais, diferentes das comuns é que estarão aptas a exercer tais cargos: "Evoca eficácia e dispõe de uma conotação de qualidade superior. Liderar obteve o significado em nosso meio social de poder e sucesso profissional".

Quando falamos do poder, este é"a extensão na qual uma pessoa pode influenciar outra para fazer algo. [...] Apesar de as bases do poder serem discutidas como características do supervisor, o poder surge na interação entre subordinado e supervisor" (Spector, 2012, p. 346-347).

É possível também classificarmos as bases do poder, segmentando-0 em poder do conhecimento, da referência, legítimo, poder da recompensa e poder da coerção. (French; Raven, 1959 como citado em Spector, 2012, p. 347). Nas organizações há também o poder político, que tem como objetivo o controle dos processos decisórios: "a ação política é o processo pelo qual as pessoas conquistam e protegem seu poder na organização" (Yukl, 1989 como citado em Spector, 2012, p. 348). Desta forma, assumir as posições estratégicas dentro de uma organização garante poder de decisão sobre estruturas, informações, pessoas e discursos. Spector (2012) coloca que a habilidade política é um importante componente já que a base da liderança é influenciar os demais. Nesta linha, a palavra networking - rede de relacionamentos imprescindível para a ascensão profissional e garantia de "segurança" ao líder, que tem aliados confiáveis - assumiu espaço entre o discurso dos trabalhadores e das organizações.

Existem diversas formas de compreender a liderança, mas o interessante é que ao nos concentrarmos na díade subordinado-supervisor pela teoria da interação líder-membro, de acordo com Dansereau (1975 como citado em Spector, 2012), percebe-se que demais pesquisas sobre o tema têm suas limitações na crença de que grupos de trabalho são homogêneos, desconsiderando particularidades da relação entre líder e cada subordinado. 
Esta e tantas outras abordagens bem como as possíveis formas de atuação de um líder nos auxiliarão na compreensão de seu mundo interno, já que não devemos esquecer que antes de um cargo ou representante de uma empresa, o líder é indivíduo. Por ser indivíduo, carrega seu imaginário da liderança, suas crenças e modelos que construiu na infância, modelos e bases estas que fazem com que signifique o mundo.

Como será então que um líder define qual é a melhor maneira de agir? É capaz de discernir entre os modelos que deve assumir ou é levado pelos discursos da organização e por seu imaginário, seus fantasmas? Homens e mulheres atuam da mesma forma? Sobre este último questionamento Spector (2012, p. 365) também coloca suas considerações, dizendo que "nossos estereótipos relativos a homens e mulheres sugerem que as muIheres se preocupariam mais com os sentimentos e o bem-estar emocional dos subordinados (consideração), enquanto os homens se voltariam mais à realização do trabalho (estrutura de iniciação)". A resposta é mais complexa do que associações entre o esperado da mulher e do homem. Dejours (1998) discutirá, por exemplo, a respeito da virilidade necessária, tanto para homens quanto para mulheres, para a manutenção de suas posições.

Ainda se pensarmos na análise de Dejours a respeito deste tema, poderemos observar nos estudos de Spector $(2012$, p. 373) que: " [... os estilos estereotipados de homens apresentando alto nível de estrutura e mulheres apresentando alto nível de consideração foram encontrados em pesquisas de laboratório, com estudantes, mas não em estudos em campo, com líderes reais. " Disto, serão extraídas duas hipóteses. " [...] um contexto organizacional inclui restrições e requisitos ambientais que podem forçar líderes homens e mulheres a adotar estilos similares [...] ou as organizações podem selecionar mulheres que apresentem estilos de liderança similares aos dos homens" (Spector, 2012, p. 373).

Independente destas análises entre os sexos, a liderança tornou-se tema de interesse em todas as esferas, recaindo sobre ela uma responsabilidade de tornar prósperas quaisquer organizações: "0 interesse pela temática da liderança é um dos imperativos atuais. [...] As empresas buscam intensamente líderes atuantes, competentes e eficazes como uma questão de sobrevivência no mercado competitivo" (Gomes, 2017, p. 84).

Justamente por esta hipervalorização a liderança recebe os olhares e julgamentos de todos, aumentando o grau de competência exigida dos líderes, que devem possuir demasiada inteligência, capacidade crítica sobretudo, iniciativa, planejamento, disponibilidade total ao trabalho, visão empreendedora, entre outras características: "A mensagem imposta é: controlem e previnam tudo, até o que é imprevisível, para serem considerados profissionais competentes, mesmo que a única constância que se possa vislumbrar nos ambientes empresariais atuais seja a mudança" (Gomes, 2017, p. 85).

São exigidas características cada vez mais heróicas para que estes estejam aptos a participar dos mais diversos e desafiadores ambientes organizacionais. Desta forma se dá a seleção natural nas empresas. Na visão de Nobre (2017, p. 87), "As empresas têm optado por uma perspectiva estratégica onde se busca uma performance excelente tanto do líder quanto de seus liderados. Deste modo, ao líder é exigido como característica fundamental a capacidade de adaptabilidade às mais adversas situações"

\section{O discurso organizacional}

0 discurso, transmitido por meio da cultura e disseminado pelos "dirigentes" (líderes ou os profissionais dos Recursos Humanos), tem o papel de moldar o pensamento do trabalhador, voltando-0 para uma posição de cooperação (ou submissão). De acordo com Antonio Freddo (2001, p. 21)“[...] o sujeito não coopera de modo espontâneo e consciente, a não ser que em sua atuação esteja imbuído de um senso de oportunismo e queira, de algum modo, levar vantagem enquanto desempenha seu papel na organização".

Existe denominação também de imaginário para a cultura da organização, como uma espécie de imaginário organizacional, algo que é compartilhado pelos dirigentes ou por todos os empregados, mostrando a importância do imaginário para a identidade da empresa. 0 trabalhador "vestirá a camisa"da empresa não como dirigente, mas como locutor do poder político ali presente, sendo manipulado, diferentemente do dirigente, uma vez que, segundo o autor, este último tem consciência do conteúdo ideológico, alienante, do discurso, pois o produz, e sua missão é a manipulação e a doutrinação. Segundo Gomes (2017), cabe então ao líder fazer a intermediação entre organização (transmitindo a ideologia desta) e demais trabalhadores. Este comportamento tem como objetivo direcionar o trabalhador para a produtividade e lucratividade.

Com estes pontos colocados no lugar, é possível agora levantar alguns questionamentos a respeito do discurso. 0 dirigente possui de fato o real discernimento e crítica para avaliar o discurso que dissemina? Os líderes das grandes empresas reconhecem por trás da cultura e discurso organizacionais as formas de manipulação e direcionamento do trabalhador? Ou seriam eles mesmos também manipulados? Se a cultura organizacional for considerada como o tabu transmitido pelo chefe da tribo, há de se considerar que o senso crítico do interlocutor esteja prejudicado. 0 que fica marcado então é o aprendizado da obediência por parte dos trabalhadores, segundo Antonio Freddo, pelo processo educativo que conduz a este aprendizado nas organizações.

Faria \& Meneghetti (2007 como citado em Gomes, 2017) nos contam que as organizações têm poder de influenciar o inconsciente de seus membros tornando-os aliados na manutenção deste mesmo poder, e ao mesmo tempo são os ambientes nos quais os seres humanos encontram a realização de muitos dos seus desejos e anseios. Logo, para entendermos os processos sociais de controle e poder precisamos explorar a vida psíquica dos indivíduos e a vida psíquica das organizações.

Levando em consideração o exposto por Gomes, a legitimidade do discurso organizacional, pela visão de Freddo, terá dois principais caminhos. 0 primeiro é "vestir a camisa" buscando tirar proveito e reconhecendo 0 conteúdo ideológico, e o segundo, que envolve a interiorização, por meio de consentimento com a doutrinação. Desta forma, o caminho pela excelência segue paralelo ao caminho do adoecimento. É transmitido ao trabalhador 0 discurso de que precisa ter o sentimento de dono, de fazer parte do time, como se fosse um chefe de família, mas não é passado a ele o preço que se paga por esta postura. 0 sentimento de dono é apenas isto, sentimento, já que na realidade o "benefício" de participação nos lucros máscara o distanciamento entre a conta do trabalhador e as contas milionárias dos reais donos da empresa.

Visto que independente do caminho escolhido (ou de certa forma imposto) pelo líder, frente à cultura organizacional, percebe-se que em qualquer uma das possibilidades o sujeito sofrerá as influências deste mecanismo, desta relação de poder, da racionalidade instrumental que (a fim de manter 
uma prática alienante) "se apresenta à ação humana na organização através do discurso, como uma lógica de dominação, cuja finalidade é a preservação do inconsciente político da organização e cujo locutor se mostra um sujeito a serviço de um poder político." (Freddo, 2001, p. 24).

\section{O mundo interno dos líderes}

A busca pelo conhecimento do mundo interno do líder surge pelas influências de autores como Laurent Lapierre (1995). De acordo com Godoi et al (2017), "o grupo tem o desejo de organizar-se diante de um líder; mas, para que isso ocorra, o líder precisa acreditar fielmente em suas próprias ideias para corresponder e influenciar o grupo". A base está na crença, na energia investida nos ideais do líder e por consequência, espera-se, nos ideais da organização. De acordo com Lapierre (1995 como citado em Godoi, 2017), ”0 que vai definir o fenômeno liderança [...] éa vida psíquica do líder, ou seja, as emoções que externaliza, a forma como percebe o mundo e como age com os outros e se comporta".

Com isto pode-se perceber a importância do reconhecimento do mundo interno do líder, uma vez que este cria dentro de si um modelo de liderança que acredita dever ser seguido, contendo seus fantasmas, suas necessidades, desejos e inseguranças, e estes por sua vez, se não muito claros para o líder, o tornarão vítima de si mesmo ou seus subordinados vítima deles. Portanto, a liderança não pode ser compreendida apenas pelas teorias administrativas, recebendo um cuidado mais completo quando consideramos estes outros aspectos. Outro exemplo disto reside no fato de que, para Faria e Meneghetti (2007 como citado em Gomes, 2017) estudando as relações de poder e controle nas organizações, nota-se as relações entre organização e inconsciente como conceitos de mútua influência, sendo necessárias tanto uma compreensão histórica da sociedade quanto uma compreensão de questões inter e intrapessoais de seus membros.

Com base nisto, precisamos considerar também as relações de poder e mecanismos sociais existentes, e quando tratamos das relações de poder dentro de uma organização, não estamos falando somente do poder político, mas sim do poder sobre os outros, da possibilidade de controle, o poder na relação em si. Como Lapierre (1995) pontua, os medos e a ambivalência que suscita a liderança dizem respeito a questões do poder que detém um indivíduo sobre os outros e mais particularmente à possibilidade de se fazer cumprir desejos e necessidades do poder do líder em determinada situação.

Neste espaço representado por medos e inseguranças, o imaginário dos líderes (resultado das projeções, construções intelectuais do próprio sujeito com base em suas memórias) e os fantasmas (trama ou drama que dão sentido à vida de uma pessoa, por meio de defesas, paixões ou obsessões) destes que de acordo com Lapierre (1995) podem ser classificados em conscientes e inconscientes, representam os elementos que não estão claramente aparentes, sendo necessário investigá-los para compreender a realidade do líder. É 0 fantasma que confere sentido e direção ao modo de pensar e de agir. Nesta investigação entram em contato a subjetividade do líder e a do pesquisador, constituindo sempre uma relação ao mínimo dual para compreensão do imaginário. Ainda segundo Lapierre (1995), Erik Erikson considerou que os fantasmas, por justaposição, constituem o estilo de liderança e que quando bem integrado, o sujeito apresenta seus fantasmas transformados, dificultando 0 acesso às suas formas mais primitivas e brutais.
Olhando agora para o "Iado obscuro da liderança", não são raros os casos, principalmente entre os CEO (Chief Executive Officer - Diretor Executivo, em português), relacionados ao narcisismo, embora acredite-se que certa dose deste seja importante ao exercer o cargo. Propõe-se então uma distinção entre narcisismo reativo e outro que é construtivo. "Os narcisistas construtivos seriam aqueles que têm uma boa base familiar, com estrutura de segurança que dá suporte para saber o que quer ser [...], porém não são tão envolvidos com os outros, apesar de garantirem uma boa convivência". (Vries, 2003 como citado em Godoi et al, 2017, p. 604).

Já o narcisismo reativo está associado ao sujeito que sente não ter sido amado o suficiente, tendo como combustível o fantasma do sucesso sem limite. 0 narcisista reativo tem o desejo de dominar de modo frio, implacável, grandioso e exibicionista. Estas e outras segmentações do narcisismo são discutidas por Lapierre em "Chanel, o espírito de independência e a liberdade criadora", capítulo que compõe sua obra, abordando a vida de Chanel enquanto líder, iniciando com uma contextualização de sua infância.

\section{Os mecanismos de manipulação e as injustiças no trabalho}

Conforme comentado anteriormente, a pressão para mal trabalhar, para mal fazer, está presente na vida das organizações e é fruto de alianças entre os meios de produção, as visões focadas em lucratividade e a falta de preocupação com a qualidade. Dejours (1998) já pontuava estes temas, que com o passar do tempo agravaram-se. A obra de Dejours se mantém atual pois os mecanismos aos quais nos referimos não tiveram grandes mudanças. Os termos usados para descrever ou mascarar são outros, mas em essência tem os mesmos funcionamentos. De acordo com Dejours (1998, p. 31), independentemente das competências e dos conhecimentos do trabalhador, este "não pode fazê-lo porque o impedem as pressões sociais do trabalho. Colegas criam-Ihe obstáculos, o ambiente social é péssimo, cada qual trabalha por si, enquanto todos sonegam informações [...]".

Os bloqueios para efetuar o trabalho da forma correta são fonte de sofrimento ao trabalhador. As lideranças fazem parte disso, contribuindo para a criação de obstáculos destinados aos que estão abaixo, embora também sofram da mesma tática por parte dos donos das empresas. Estas situações têm como característica aparecer de formas sutis, como negar acesso a determinadas informações ou dificultar o trabalho dos demais de forma não colaborativa, que: "podem contribuir para tornar aceitável aquilo que não deveria sê-lo. Por isso as estratégias defensivas cumprem papel paradoxal, porém capital, nas motivações subjetivas da dominação a que já nos referimos" (Dejours, 1998, p. 36).

Caso estas dificuldades no ambiente de trabalho estejam ligadas ao surgimento de al guma patologia, esta não poderá ser abordada, uma vez que falar sobre isto nas organizações é entendido, por vezes, como "mexer em um vespeiro". Dejours (1998) afirma que toda abordagem de questões subjetivas e problemas psicológicos são tratados com resistência por prejudicarem a ação coletiva e valorizarem 0 individual.

A fim de legitimar as práticas de manipulação e de perpetuar as regras da organização, surge o conceito de "recursos humanos", fruto também de movimentos decorrentes das organizações trabalhistas, como Dejours (1998) coloca esta área ligada à introdução de novos métodos e conceitos 
como "cultura empresarial, projeto institucional, mobilização organizacional", anestesiando assim a capacidade de resistência e de ação coletiva das organizações sindicais. Fora a ideia da área de recursos humanos como uma contribuinte para a legitimação das práticas de controle, como coloca Gomes (2017), é contribuinte também para o surgimento de conflitos internos no líder a percepção, por parte dele mesmo, de qual posição ocupa em um sistema de classes capitalista, visto que em partes ele é representante do controle de capital e simultaneamente, assume a posição de empregado assalariado.

Devemos levar em consideração todos os pontos ligados à liderança e listados anteriormente, para ponderar sobre as influências que esta sofre da cultura organizacional e influências que também causa nesta cultura, podendo contribuir para torná-la facilitadora de um ambiente organizacional saudável e colaborativo ou disfuncional e emergente de diversas patologias e fonte de sofrimento no trabalho. A personalidade do líder se molda ao contato com a cultura, assim como este também irá moldá-la para uso a favor de seus objetivos. Além do contato com a cultura organizacional, há também as influências do modelo de sucesso da sociedade contemporânea, o qual, segundo Gomes (2017, p. 86), é reflexo das prioridades pessoais influenciadas pelo sistema capitalista moderno: " [...] emerge uma preocupação acentuada com a realização individual, com a beleza e a juventude, a felicidade e 0 sucesso pessoal pautados em uma ideologia que prevalece a busca do prazer individual sobre todas as coisas".

Aos que não alcançam este ideal de sucesso resta um passeio turístico pelos bosques de sofrimento psíquico, imersos na crença de que não foram bons o suficiente ou de que possuem limitações que os bloqueiam. 0 sofrimento psíquico por sua vez sofre de banalização: "0 estresse foi naturalizado como um produto da vida cotidiana, associado, dentre outras coisas, à luta diária em corresponder à imagem idealizada pela profissão, muitas vezes, inacessivel" (Gomes, 2017, p. 87).

Dejours (1998), afirma que a informação destinada aos empregados (gerentes ou operários) é adulterada, mas é por meio dela que perdura a mobilização subjetiva do gerente. 0 nome dado à estratégia por trás desta adulteração de informação é a "estratégia da distorção comunicacional". 0 problema surge quando se nota que há a participação das pessoas de bem neste mal como sistema de gestão. Soa como uma acusação à gestão nas empresas, e o é, porém Dejours acredita que estes estão em posição de perversos, paranoicos, abnegados ou idealistas apaixonados. Retomando nossa base psicanalítica, os fatores acima expostos contribuem para que recaia sobre o trabalhador (não excluindo o líder) a ameaça da castração, que é, de acordo com Dejours (1998), nestes casos um instrumento de banalização do mal, invertendo o ideal de justiça através da mediação com a ameaça de castração. A angústia dessa castração permanece no inconsciente do adulto.

Existiria então uma busca pelo trabalho como fonte de sublimação e uma busca pela submissão a alguém cujo poder é tão forte que geraria a ameaça de castração novamente? Uma pergunta muito complexa para que façamos afirmações por uma ótica reduzida. 0 que de fato poderemos constatar é que para afirmação de seus altos níveis de virilidade e para que não deixem de ser reconhecidos como homens, para que possam se afirmar sexualmente e mostrar à sociedade que não são covardes, os sujeitos se colocam em situação de "trabalho sujo" e se transformam em "colaboradores", como os chama Dejours (1998) e todo o restante do mundo corporativo que busca em palavras atualizadas esconder o sentido daquilo que já existia em ocasião das revoluções industriais.
A virilidade para Dejours assume um sentido de ser capaz de cometer violência contra outrem, em nome "do exercício, da demonstração ou do restabelecimento do domínio e do poder sobre o outro". (Dejours, 1998, p. 81). É equivocado associarmos a virilidade com a masculinidade. A virilidade da qual falamos é fruto de construções sociais que também tornam passíveis de exclusão aqueles que não a exercem: " [...] recusar-se energicamente a fazê-lo, em nome do bem, correndo assim o risco de ser denunciado, punido e até incluído na próxima lista de demissões". (Dejours, 1998, p. 82).

\section{Considerações finais}

Dado todo o desenvolvimento desta pesquisa, pudemos observar por variados vieses, muitos destes ligados à psicanálise, uma série de influências sobre os líderes. Desde o início tivemos uma proposta exploratória com o intuito de que a pesquisa se torne uma introdução a estudos posteriores. Pôde-se perceber a existência de diversas visões da liderança, com enfoques diferentes e, portanto, fica claro que para uma melhor compreensão do fenômeno liderança faz-se necessário considerar todos os seus aspectos.

Nossa jornada através do tema assume caráter mais crítico quando envolvemos Christophe Dejours. 0 intuito é mostrar o líder como um sujeito na condição de trabalhador comum, que por vezes não se reconhece enquanto um, e segue com suas práticas que trazem forte impacto negativo na vida de seus subordinados e em sua própria. Ser um "colaborador do trabalho sujo", como vimos, não necessariamente caracteriza um crime, mas traz consequências na vida e na saúde dos trabalhadores.

Se esta pesquisa pôde esclarecer al gum ponto, acredita-se que este seja o fato de que se encontrou no discurso e cultura organizacionais (aliados aos poderes conferidos a determinados cargos) as influências no modo de agir do trabalhador direcionando-o para uma função de retransmissor passível de exclusão caso não a cumpra.

Restam inúmeras dúvidas e questionamentos a serem feitos sobre 0 mundo do trabalho e suas implicações na vida dos sujeitos, reconhecendo sua dimensão multifatorial. A questão da virilidade nas organizações, as influências da sociedade na qual uma organização está inserida, a história de vida do próprio líder, os novos métodos e exigências do mundo do trabalho, dentre tantos outros assuntos que ainda precisam ser esclarecidos. Neste mesmo sentido, associa-se à contribuição de Morgan (1996) quando coloca que "As organizações não são condicionadas somente pelos seus respectivos ambientes; são também moldadas pelos interesses inconscientes dos seus membros e pelas forças inconscientes que determinam as sociedades nas quais elas existem."

0 anseio é de que seja realizada uma pesquisa de campo capaz de mostrar mais de perto, em contato direto com os líderes, como os mecanismos de manipulação e seus discursos estão enraizados na forma de agir, de forma imperceptível para qualquer pessoa que não tenha como propósito investiga-los e trazê-los à tona.

\section{Referências}

Dejours, C. (1998). A Banalização da Injustiça Social (7a ed.). São Paulo, SP: Editora Fundação Getúlio Vargas.

Folberg, M.N. \& Maggi, N.R. (2002). Declínio da Função Paterna e Dialética da Simbolizaçãa. Estilos da Clínica, 7(13). 
Freddo, A. C. (2001). O Espelho da Alienação. São Paulo, SP: Cad. Posgrad, Editora Leopoldianum.

Freud, S. (2013). Totem e Tabu. Porto Alegre, RS: Editora L\&PM Pocket. (Obra original publicada em 1913)

Godoi, C.K., Cargnin, F.R.G., Uchôa, A.G.F. (2017). Manifestações Inconscientes na Relação Líder-Liderado: contribuições da teoria psicanalítica aos estudos organizacionais. Cad. EBAPE.BR, 15(3), (paginação irregular).

Gomes, A. M. G. (2017). Liderança e Personalidade: Reflexões Sobre o Sofrimento Psíquico no Trabalho. Revista de Psicologia, 8(2), 83-91.

Lapierre, L. (1995). Imaginário e Liderança: na Sociedade, no Governo, nas Empresas ena Mídia. 1. ed. São Paulo, SP: Atlas.

Laplanche, J. \& Pontalis, J. B. (2001). Vocabulário da psicanálise. (4a ed.). São Paulo, SP: Martins Fontes.

Morgan, G. (1996). Imagens da organização. São Paulo, SP: Atlas.

Nobre, T.L. \& Mello, R.C.H. (2017). Liderança nas Organizações: um estudo sobre esta competência na atualidade. Revista lluminart, 14(9).

Spector, P. E. (1986). Psicologia nas organizações. São Paulo, SP: Editora Atlas. 